Berg I.L., Lombardo, S., and Lædre, O.. (2018). "Innovation with creative collaborative practices" In: Proc. 26 th Annual Conference of the International. Group for Lean Construction (IGLC), González, V.A. (ed.), Chennai, India, pp. 358-369. DOI: doi.org/10.24928/2018/0397. Available at: www.iglc.net.

\title{
INNOVATION WITH CREATIVE COLLABORATIVE PRACTICES
}

\author{
Ingrid Løvendahl Berg ${ }^{1}$, Sebastiano Lombardo², Ola Lædre ${ }^{3}$
}

\begin{abstract}
Lean is about solving problems related to reducing waste while maximizing value. The project team of the construction project Bispevika in Norway is working on how creative collaborative practices can be performed in problem-solving processes. This paper considers following research questions: Which creative collaborative practices are implemented in Bispevika? What are the experiences of these practices? How to improve these practices in future projects? In addition to observations on site within design and procurement, interviews of the project managers as well as a document study based on received project material is carried out to identify creative collaborative practices. A literature study on trust in collaboration, creative processes and creativity and innovation in lean is also presented. The engagement of an innovation manager as a facilitator combined with his own research on creative practices contributes to the overall vision of being an innovative project. The executed method is based on a four-phased process leading to the choice of best solution to a case. By using a strategy of creating winning teams and focusing on trust in these collaborations, the project is aiming at innovating the way projects are managed in the future. Identified creative collaborative practices with proposed adjustments are presented.
\end{abstract}

\section{KEYWORDS}

Creativity, collaboration, innovation, trust, problem-solving processes

\section{INTRODUCTION}

The goal of planning and executing projects while minimizing waste and maximising value comes from the mindset of lean construction (Ballard and Howell, 2003), and is increasingly implemented in a conservative and traditionally bounded industry, as construction is perceived today. Simultaneously, a complex project design demands uniqueness and higher level of specialization (Lombardo, 2014), yielding a need for interaction and involvement of multidisciplinary stakeholders on another level than before (Bygballe and Swärd, 2014). Problem-solving processes are often carried out as

1 M. Sc. Student, Dept. of Civil and Transport Engineering, NTNU - Norwegian University of Science and Technology, Trondheim, Norway, +4798049668, ingridlb@stud.ntnu.no

2 Adjunct Assosiate Professor, BI Norwegian Business School, Oslo, Norway, +4793012003, sebastiano.lombardo@bi.no

3 Associate professor, Dept. of Civil and Transport Engineering, NTNU - Norwegian University of Science and Technology, Trondheim, Norway, +4791189938, ola.ladre@ntnu.no 
mapping of previous solutions and experiences, moving along patterns of existing knowledge (de Bono, 2009), thus limiting the number of possibilities. By using a structured and conscious approach towards creative processes leading to innovative and improved solutions (Amabile et al., 2002), future projects are able to combine the mindset of lean with the demand for complexity and uniqueness. Implementing problemsolving practices of this kind requires close facilitation (Lombardo, 2014; Amabile and Khaire, 2008) with internal as well as external, multidisciplinary stakeholders, and should aim at crossing these established patterns in problem-solving processes. Thus, creative practices demands and yields collaboration, as a partnering relationship requires interaction to reach its full potential (Bygballe et al., 2010). In total, a new approach to problem-solving practices should involve the two elements creativity and collaboration, while emphasizing the development of innovative solutions.

This study aims to discover how creative cooperative practices are used in production of innovative solutions in a multidisciplinary engineering project. More specifically, to identify:

1. Creative collaborative practices concerning procurement and design in a case study,

2. The experiences of these practices from the main contractor's point of view, and

3. The potential for improvement of these practices for future projects.

Regarding limitations, the first step has been to narrow the scope to concern mainly two project activities, whereas procurement and design has been chosen as the most relevant activities. Further, the study is restricted to the view of the main contractor. The research period is limited to a timeframe of six months, which could have an impact on the results regarding the current project phase. The time limitation also makes the followup of a specific case through its respective phases of the creative process constraining. The solution has thus been to collect a representative number of observations from each phase, not taking the continuity of each case into consideration.

\section{THEORETICAL FRAMEWORK}

Based on the topics presented in the introduction, it appears interesting to take a closer look at research treating topics related to the creation of trust in collaboration, as it is considered a critical element in obtaining a creative collaboration (Swärd, 2016). How creativity and innovation are mediated with the concept of a lean mindset raises some controversies to be treated further on in this chapter. Other topics needing to be explored are creativity by its definition and creative processes in problem solving tasks. The aim of this chapter is primarily to map how these topics have been treated and explored in existing research and secondly to identify lack of knowledge about how mentioned topics interact with and are dependent of each other (Blumberg et al., 2005). 


\section{TRUST IN COLLABORATION}

Several researchers within creativity and innovation are pointing towards the need for trust, affect and reciprocity as a prerequisite when developing a problem-solving and creative environment (Bygballe et al., 2010; Swärd, 2016). Affect and creativity are linked by positive affect facilitating cognitive variations (Amabile et al., 2005). These variations yield new associations which finally leads to creativity. Reciprocity is defined as a social norm in the shape of an expected repayment for an action between two parties, a behaviour which may lead to increased trust (Swärd, 2016). The response time of a reciprocity increases with the significance or investment of the reciprocity, and will also contribute to a larger sense of trust in a long-term relation. In order to optimize the use of reciprocity and then the development of trust, the necessity of psychological safety in the collaboration between multidisciplinary actors at a workplace or a project needs to be announced and established (Edmondson, 2012). Psychological safety is critical when establishing working teams beyond a business relation. This must imply that when conditions for trust are present, the project is more likely to succeed in implementing change.

\section{CREATIVITY AND INNOVATION IN LEAN}

Creativity has been looked upon as an individual and abstract skill, with low ability of measuring effect or size (Klausen, 2010; Kaufmann, 2003). Among other misconceptions are the idea of creativity only being performed as an activity of brainstorming (de Bono, 1995) and that the best creative solutions are achieved under time pressure (Amabile et al., 2002). There are several challenges related to the definition of creativity, and Klausen (2010) reminds us to never confuse novelty alone for being creative. As problem-solving processes traditionally consist of moving along patterns elaborated from previous experiences and existing knowledge, crossing across these patterns can enable serious creativity in the form of lateral thinking (de Bono, 1995).

As implementing change in the construction sector is dependent on incorporating new knowledge into existing routines (Bygballe and Swärd, 2014), there is reason to believe that relation and interaction with external stakeholders are critical elements for success in concepts like lean construction. The motivation for change needs to come from a belief of increased competitiveness in the market (Bygballe and Swärd, 2014). In other words believing that change could make the organisation more profitable and attractive to other stakeholders. By bringing creativity and innovation into the concept of lean, an organisation's confidence, attitude towards problems, motivation and engagement are among the requirements for optimal execution (Johnstone et al., 2011). The concept of lean construction emphasizes resource-use and process-flow in optimisation, while creativity is proven to reach its potential when time is an adequate resource (Amabile et al., 2002). Thus, there is a controversial balance to be upheld in uniting creative practices with a lean mindset. One concern is related to workers developing an excellent planning skill while reducing their creative skill, towards neglecting or strangling innovative, creative work (Bygballe and Swärd, 2014). Organisational practices mediate the link between innovation and knowledge-sharing by collaboration and interaction (Foss et al., 
2011), and interaction should thus be taken into account when managing creativity and innovation in a lean-environment. One solution must be to facilitate consciousness towards the definition of creativity, and what creative practices are intended to achieve.

\section{CREATIVE PROCESSES}

As a possible solution to the challenges regarding problem solving processes in optimization of innovative solutions, lateral thinking should be enabled into practices suited for a given project. A possible practice for creative processes, adjusted to the complexity of multi-disciplinary project teams, is presented in the thesis of Lombardo (2014). The practice consists of four phases; focus, idea generation, assessment and evaluation, and finally choice of solution. Each phase follow a certain layout regarding how they should be carried out. The method emphasizes establishment of a focus rather than a problem, and the use of this as a guide towards creating ideas and further evaluating and choosing possible solutions. The method clearly describes how to facilitate and explore the potential of creative sessions, as well as how ideas and potential solutions should be documented, assessed and evaluated in order to be implemented and executed in real life. Lombardo (2014) also includes experience-based do's and dont's along with every phase, preparing the reader for potential pitfalls in a creative session. It is particularly the idea generation-phase which demands creativity, as the creative interaction between the stakeholders is put at the core of the problem-solving process. The practice aims at leveraging the creative resources by stimulating interaction. Within each phase, a number of actions are performed in order to provoke creativity, requiring participants to know the usual approach to a problem in order to be appropriate.Absence of previous knowledge - ignorance - is known to be a potential source to creativity (de Bono, 1995), making the practice unnecessary. This type of generation or exploration of creativity requires having an adequate time frame while avoiding an excessive number of participants in the collaboration (Amabile et al., 2002).

\section{METHODOLOGY}

The chosen research methods are based on practice as unit of analysis, consisting of data collaboration and data analysis. Initially, a literature study has been performed in order to map current research on the topic field. Data collaboration in the case study is carried out through initial, qualitative interviews in addition to document studies and observations.

Findings from the literature study are presented in the theoretical framework as the current state of research related to the topic of the study (Blumberg et al., 2005). Recommendations from supervisors and search-engines online are the main source to the findings. Chosen literature spans from published conference articles and journal articles to books and theses. 


\section{PRACTICE AS UNIT OF ANALYSIS: A CASE STUDY OF TEAM BISPEVIKA}

The context for this research is the case of Team Bispevika in Oslo, Norway, a project aiming to contribute to an innovative change of project management in the industry. In Norway, the interest for continous improvement and Lean Construction is relativelty high (Engebø et al., 2017). All interviewees, documents and observations are related to this case.The project is the first in a long-term goal of the main contractor to use innovation in order toincrease the added project value by $40 \%$. The plan is to reduce costs by implementing innovative solutions and increasing quality for the end-users. The ongoing project has a cost of MNOK 1109, consisting of constructing 11 buildings over $48.000 \mathrm{~m}^{2}$ at the old harbour of Oslo. Areas of innovation spans from partnering with contractors to contract strategies, and the vision affects all aspects of the project. Towards innovation, the project uses creative processes in problem solving incidents. These practices are prominent within procurement and design as chosen areas of this study, but also in production and end sale. The project management has its main workforce from one of the largest contractors in Norway, and the client is heavily involved in project execution.

\section{INTERVIEWS}

Interviews are carried out with a prepared interview guide and semi-structured to allow the interviewer to angle the questions and topics toward the relevance based on answers given by the interviewee (Yin, 2014). There are five interviews in total, and all interviewees hold key roles in the project management. The intention of the interviews has been to unveil the mindset of the project, and how they work differently than traditional construction projects. There have been challenges concerning the coordination of information given in the interviews, as the interviewees perceive different perspectives of the project as important.

\section{DOCUMENT STUDY}

There are mainly used three project documents to examine the intentional purpose and framework for the practices, contributing and supporting collected data from interviews and observations. All documents are received from the project management on request. The document related to the tender stage is considered a guideline for every aspect of the project, and there is thus only the chapter concerning innovation which is taken in closer consideration. The document related to creative processes in design is a guideline on how sessions in the optimization process should be carried out. Representing procurement, the chosen document presents an example of how strategies for each discipline are developed and documented for further collaboration.

\section{OBSERVATIONS}

Observations consisted of participation in sessions related to procurement and design with the innovation manager operating as the session's facilitator. When planning the observations, the method of Creswell (2012) was used with the intention to follow 
meetings in procurement and design as a direct link to discover how practice is performed in everyday project life. Published material from the project's innovation manager was used to conduct each meeting, and recording of the observations were made through taking minutes. The phase concerning choice of final solution has been left out, as it is considered to be of less interest to the research questions. A matrix of the observations made within each case, activity and process phase is presented in table 1 . The limited time frame made it demanding to follow each case through each process phase, thus a representative number from each phase is chosen.

Table 1: Observations of the case study

\begin{tabular}{lccc}
\hline \multicolumn{1}{c}{ Topic for innovation - Activity } & Focus & $\begin{array}{c}\text { Idea } \\
\text { generation }\end{array}$ & $\begin{array}{c}\text { Evaluation \& } \\
\text { assessment }\end{array}$ \\
\hline Waste recycling - Procurement & $\mathrm{X}$ & $\mathrm{X}$ & $\mathrm{X}$ \\
Roof construction - Design & & $\mathrm{X}$ & \\
Concrete: Con Form - Procurement & $\mathrm{X}$ & $\mathrm{X}$ & $\mathrm{X}$ \\
Discipline Strategies - Procurement \& Design & $\mathrm{X}$ & & \\
Sunblind - Design & & & $\mathrm{X}$ \\
Timber - Procurement & $\mathrm{X}$ & & \\
Logistics - Procurement & & & \\
\hline
\end{tabular}

\section{FINDINGS AND DISCUSSION}

This section presents both findings and discussion of each research question under the process phases, with an aim of identifying characteristics and experiences of creative, collaborative practices in Team Bispevika and how they can be improved, as presented by the research questions. The guide for observational studies is based on the method of Lombardo (2014), elaborated in the theory section. A simplified presentation of the phases are shown in figure 1.

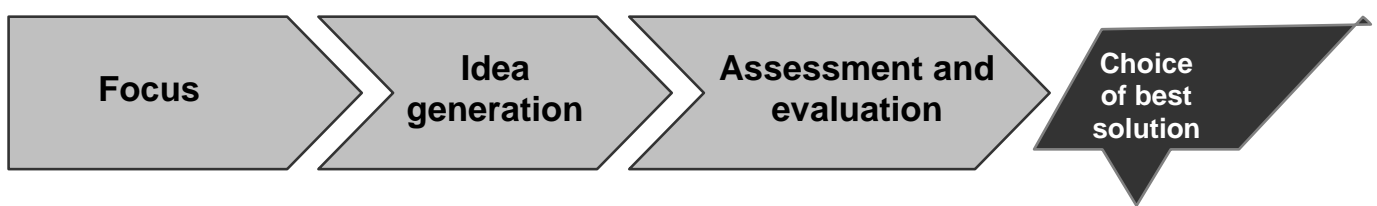

Figure 1: The phases in a creative process, freely based on Lombardo(2014).

\section{FOCUS}

Which creative and collaborative practices are identified in the focus phase?

To map the potential of each discipline within the project, the procurement team is developing different strategies for each project area in documents called Discipline 
Strategies, presenting intention and goal of each collaboration and how to work together towards improved solutions. Through process facilitation and method awareness, the project team aims at meeting increasing project complexity and client demands. This is emphasized through spending resources on engaging qualified personnel such as an innovation manager and an improvement manager to follow up creative processes, collaborative challenges and innovation management. By having these key roles on site as a part of the project management team, the chances increases of creating solutions that are tighter connected with market needs and development in a long-term perspective. Throughout the focus sessions, the innovation manager reminds the participants of the session's intention and desired outcome. This strategy is confirmed through the project documents, aiming to contribute in implementation of the creative process in daily problem-solving work:

The Innovation Manager(IM) is responsible for execution and facilitation of the project's innovation processes. IM will also plan and execute collaborative processes.

\section{What are the experiences of these practices?}

The interviews and observations unveil variation from procurement to design regarding the time frame of the focus phase, due to the current project phase and nature of the activity. Findings show that the procurement team spends more time on establishing trust and knowledge towards the project's mindset, while the pressured time-limitation in the design team rather makes the collaboration about "getting the job done". This was especially made clear through focus sessions with the concrete supplier and waste recycling, where the facilitator needed to postpone the delivery of focus criteria to the later meetings, and rather spend time on getting the new partners into the innovative mindset of the project. The final outcome of the focus phase for the two collaborations were the highly ambitious goals of $33 \%$ increased productivity for the concrete work compared to similar projects, and $99 \%$ recycled material for waste management.The observations of design are done on a more detailed level than procurement, which could explain the difference in time use. As a part of the process towards change of problemsolving practices, creating competitiveness in the market is used as a motivation for development of these practices. The project team uses a visual presentation of their longterm goal of cost reduction and quality increase throughout the focus sessions. The main delivery of the phase is a list of criteria corresponding to the problem-solving issue, mentioned and confirmed orally in sessions as well as written in project documents.

\section{How can these practices be improved in future projects?}

A change of attitude and perception takes time, and members of Team Bispevika work every day to change the stakeholders' conception of creativity, collaboration and innovation through their vision. As one of the interviewees pointed out:

None of the elements we use here in Team Bispevika are totally new and never tried out before, but the framework around how we do business gives a new perspective on how projects can be managed and executed in the future. 
Preparation of the focus phase should consist of creating knowledge and awareness towards the method itself, as it takes time and effort to realize that creativity not necessarily equals novelty. Interviewees also request a tool to determine deadlines and timeframes related to the creative collaborative practices, and propose a flowchart or timeline as a possible future solution. The tool should cover all project activities, as they are closely intertwined when planning each part and process. In addition, the identification of stakeholders and their interests in the current problem or challenge could be closer examined in the focus phase.

\section{IDEA GENERATION}

\section{Which creative and collaborative practices are identified in the idea generation phase?}

The traditionally presumed way of executing a creative phase solemnly through a brainstorm determined by individual skills as presented in the theoretical framework, is clearly disproved through observations and interviews of the case study. The project team invites a varied and representative selection of stakeholders to join and collaborate in these sessions, as they believe that different minds spur several associations, yielding more creativity and finally better ideas. Highly skilled and experienced consultants in design emphasizes the need of using constraint-shattering practices, aiming to find new angles to old challenges. This is connected to the concept of crossing established patterns in lateral thinking.

\section{What are the experiences of these practices?}

Observations and interviews of sessions in design amplify the impression of a struggle to document each idea as they progress throughout the session. When participants are new to the practice, it seems easy to lose focus and start an immediate evaluation of a presented idea, as opposed to keep focus on preserving the creative aspect of each idea through registration. In the session of designing new solutions to a roof construction, the team used a smart board to register all ideas digital, consecutively and in an organised matter. Regarding idea generation in procurement, all contributions are visibly anchored in the business model of each sub-contractor or collaborative partner. The project team have taken several actions to create a sharing culture where all stakeholders are meant and expected to contribute in creative problem-solving processes. Among the most visible actions are co-location of external design consultants and sub-contractors on site and feedback-surveys to measure the subjective effects and experiences of a session or meeting. These actions aim at creating psychological safety for each and every participant and contribute to a vision of every stakeholder pulling in the same direction. The delivery of the idea generation phase is a list of registered ideas, ready to be further treated and evaluated.

\section{How can these practices be improved in future projects?}

High speed and time pressure related to the design process makes it demanding to spend resources on developing creative collaborative practices, and the implementation of the 
current innovation practice needs adjustments in order to fit the daily workload within design. As the current time frame is limited, new solutions need to justify providing time on implementation. These adjustments should be able to bring out the potential of invested resources in the project and not only become time-consuming. Through focusing on expected preparation from participants ahead of each session, the total creative collaborative contribution can increase, and quality of the ideas could elevate. In addition, challenging participants in expanding their creative space by using techniques for association and value chains should be included in sessions.

\section{IDEA ASSESSMENT AND EVALUATION}

\section{Which creative and collaborative practices are identified in the idea assessment and evaluation phase?}

The project team have - through stating the practice in tendering documents - chose to focus on creating winning teams, aiming to increase the collaborative environment by using an open-minded strategy:

We will work together on a long-term perspective, and time spent on building trust is time well spent. (...) Respect for the skill of one another is another central premise, and not to mention getting acquainted as personal individuals, regardless of position.

This relates to the creation of psychological safety (Edmondson, 2012) as well as affect (Amabile et al., 2002). The project team works from a mindset that implies the following:

I know you $\rightarrow$ Wehave an established relatedness $\rightarrow$ I feel safe $\rightarrow$ I see more solutions

This implication is particularly visible through the procurement strategy, confirmed by the interviewees. In design, using a matrix to evaluate and map ideas according to chosen evaluation criterias creates a basis for the assessment and evaluation phase, a practice relating directly to the findings of Lombardo (2014).

\section{What are the experiences of these practices?}

When discussing and evaluating possible solutions during these sessions, the facilitator encourages an open dialogue between stakeholders to unveil biases and avoid anyone feeling bypassed. This mindset is clearly appreciated by external stakeholders, as feedback is given during sessions and through positive reciprocity in a long-term perspective. Reciprocity is shown through taking risk related to resource use as economical contribution, time spent on development of new, collaborative solutions and follow-ups of the chosen practices. Observations and interviews shows how close and careful guidance from the facilitator is necessary when sorting and categorizing generated ideas, as the practice is new to most stakeholders. During the evaluation phase, the facilitator must keep in mind the existing solution as a full-fledged alternative to consider, in order for the new ideas to be realistic alternatives. When the goal - as stated in project documents - is to leverage the creative resources, the innovation manager creates strength and credibility towards the chosen practice by using methodology recovered from his own research. Making it easier to correct unwanted execution of the practices as well as increasing chances for replication in future projects are desired results of using the framework of Lombardo (2014) in combination with engaging him as head 
of innovation and facilitator. The session's delivery is a complete list of possible and realistic solutions ready to be implemented to the daily work of design or procurement.

\section{How can these practices be improved in future projects?}

By creating an adequate time frame and limiting the number of participants as described in the theory section, the idea assessment and evaluation phase improves in terms of quality and resource use. In addition, observations show that biased and manipulated idea evaluation in design can be avoided by creating and preparing relevant evaluation criteria ahead of evaluation, in order to reveal the difference in advantages of alternatives. Interviewees point out that the effect of winning teams should at a given point in the project be measured as a guide of expected success by completion with regard to collaboration. They request a measurement practice limited to the most interesting parametres for success in a multidisciplinary engineering team.

\section{SUMMING UP AND FURTHER RESEARCH}

A proposed description of identified collaborative creative practices in production of innovative solutions in a multidisciplinary engineering project are presented in figure 2 , based on key takeaways from findings and discussion. Identified practices align well with the proposed structure of Lombardo (2014), but are added adjustments regarding preparations and outcomes from each phase in order to assure continuous development of trust and increased use of creative resources throughout the process. Team Bispevika should pay attention to the importance of continuous process facilitation, as it is critical to the establishment of trust among internal and external stakeholders. As the facilitator focuses on creating awareness towards preparation and delivery of each session, the practice gains ownership and trust from participants. It should be noticed that the presented figure is a preliminary description on how creative collaborative practices are executed in the case study at a given point of the project, made by an external observer. In other words, the practices are not complete or finalized at this point. To summarize, the identified practices which will continue to be developed into the future, could create a form of standardization and process flow, leading to a new way of executing problemsolving processes in multi-disciplinary engineering projects. Despite a traditionally conservative view on the concept of creativity, these practices can - by focusing on collaboration in the creative process - contribute to the lean concept and improve the whole construction industry in a long-term perspective. 


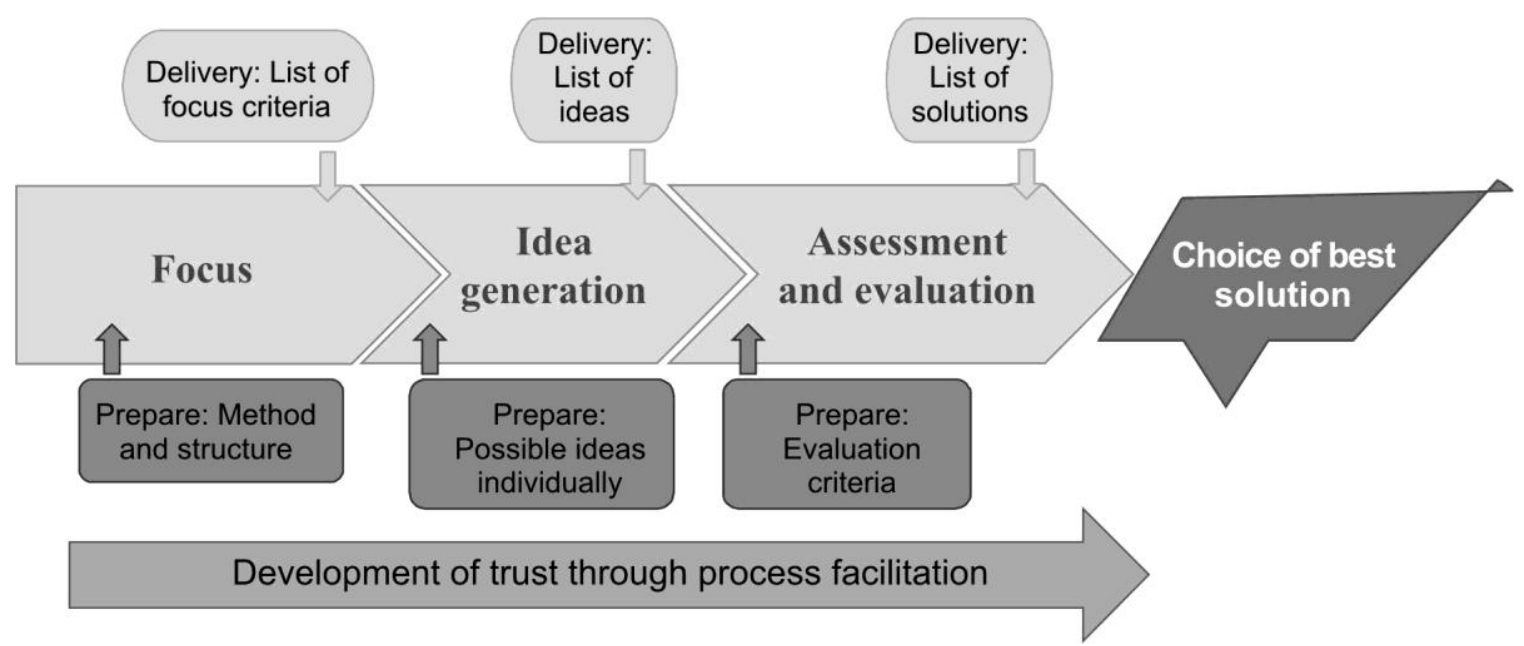

Figure 2: Identified creative collaborative practices in Team Bispevika, freely adapted from Lombardo (2014).

For future research, it would be interesting to take a closer look at how practices evolving creative processes are perceived by different sub-contractors and suppliers as well as the external design consultants to get a larger perspective. To expand the number of project activities from procurement and design to also concern property development, production and sales could result in a broader understanding of practices, as several project activities are intertwined in the daily work. To follow the project through several phases over time would also give more precise observations. Finally, it would be interesting to take a comparative look at existing desicion-making practices in the light of aleaninfluencedmethod like choosing by advantages(Arroyo et al, 2016).

\section{BIBLIOGRAPHY}

Amabile, T. M., Barsade, S. G., Mueller, J. S., and Staw, B. M. (2005). "Affect and Creativity at Work." Administrative Science Quarterly, 50(3), 367-403.

Amabile, T. M., Hadley, C. N., and Kramer, S. J. (2002). "Creativity Under the Gun." Harvard Business Review, 80(8), 52-61.

Amabile, T. M., and Khaire, M. (2008). "CREATIVITY and the ROLE OF THE LEADER." Harvard Business Review, Harvard Business School Publication Corp., $100-109$.

Arroyo, P., Tommelein, I.D., and Ballard, G. (2016). "Selecting Globally Sustainable Materials: A Case Study Using Choosing by Advantages." Journal of Construction Engineering and Management, 142(2), 05015015.

Ballard, G., and Howell, G. A. (2003). "Lean project management.” Building Research \& Information, 31(2), 119.

Bygballe, L. E., Jahre, M., and Swärd, A. (2010). "Partnering relationships in construction: A literature review." Journal of Purchasing and Supply Management, Purchasing and supply management in the construction industry, 16(4), 239-253. 
Bygballe, L. E., and Swärd, A. (2014). "Implementing Lean Construction: A Practice Perspective." Oslo.

Creswell, J. W. (2012). Educational research: planning, conducting, and evaluating quantitative and qualitative research. Pearson, Boston, Mass.

de Bono, E. (2009). Lateral Thinking: A Textbook of Creativity. Penguin UK. de Bono, E. (1995). "Serious creativity." The Journal for Quality and Participation; Cincinnati, 18(5), 12.

Edmondson, A. C. (2012). Teaming: How Organizations Learn, Innovate, and Compete in the Knowledge Economy. John Wiley \& Sons.

Eisenhardt, K. M., and Graebner, M. E. (2007). "Theory Building from Cases: Opportunities and Challenges." Academy of Management Journal, 50(1), 25-32.

Engeb $\varnothing$, A. , Drevland, F. , Lohne, J. , Shkmot, N. \& Lædre, O. 2017, 'Geographical Distribution of Interest and Publications on Lean Construction' In:, 25th Annual Conference of the International Group for Lean Construction. Heraklion, Greece, 912 Jul 2017. pp 285-292

Foss, N. J., Laursen, K., and Pedersen, T. (2011). "Linking Customer Interaction and Innovation: The Mediating Role of New Organizational Practices." Organization Science, 22(4), 980-999.

Johnstone, C., Pairaudeau, G., and Pettersson, J. A. (2011). "Creativity, innovation and lean sigma: a controversial combination?" Drug Discovery Today, 16(1), 50-57.

Kaufmann, G. (2003). "What to Measure? A new look at the concept of creativity." Scandinavian Journal of Educational Research, 47(3), 235-251.

Klausen, S. H. (2010). "The Notion of Creativity Revisited: A Philosophical Perspective on Creativity Research." Creativity Research Journal, 22(4), 347-360.

Lombardo, S. (2014). "Client-consultant interaction practices: Sources of ingenuity, value creation and strategizing." BI Norwegian Business School.

Swärd, A. (2016). "Trust, Reciprocity, and Actions: The Development of Trust in Temporary Inter-organizational Relations." Organization Studies, 37(12), 1841-1860.

Yin, R. K. (2014). Case Study Research: Design and Methods. SAGE, Los Angeles, California. 